\title{
Prospective Randomized Controlled Trial on the Use of Flexible Reinforced Laryngeal Mask Airway (LMA) during Total Thyroidectomy: Effects on Postoperative Laryngopharyngeal Symptoms: Reply
}

\author{
Chitresh Kumar • Anjali Mishra
}

Published online: 1 July 2014

(C) Société Internationale de Chirurgie 2014

\section{To the Editor,}

We read with interest the article entitled "Prospective randomized controlled trial on the use of flexible reinforced laryngeal mask airway (LMA) during total thyroidectomy: effects on postoperative laryngopharyngeal symptoms" by Ryu et al. [1]. The authors have addressed an important postoperative problem related to thyroidectomy. The incidence of postoperative dysphagia and voice change is quite high but these problems are usually not addressed as specific complications related to thyroid surgery, although obviously patients need to be counseled about them [2] We have a few comments and queries to make.

1. The authors have consciously included small tumors $(<2 \mathrm{~cm})$ and the average specimen weight was also low $(16 \mathrm{~g})$ in their study. They also mentioned in the Discussion section that strong surgical manipulation could have affected the outcome of the study. We want to know if they have attempted central compartment lymph node dissection with LMA or do they foresee any difficulty with that?
2. We have attempted a few thyroidectomies using conventional LMA and the main difficulty encountered was the displacement of the LMA when a moderatesize thyroid lobe was being delivered out from the thyroid bed. Do the authors think that a flexible reinforced LMA can be safely employed in cases of large benign goiters?

\section{References}

1. Ryu JH, Yom CK, Park DJ, Kim KH, Do SH, Yoo SH, Oh AY (2014) Prospective randomized controlled trial on the use of flexible reinforced laryngeal mask airway (LMA) during total thyroidectomy: effects on postoperative laryngopharyngeal symptoms. World J Surg 38:378-384. doi:10.1007/s00268-013-2269-1

2. Lombardi CP, Raffaelli M, D'Alatri L, Marchese MR, Rigante M, Paludetti G, Bellantone R (2006) Voice and swallowing changes after thyroidectomy in patients without inferior laryngeal nerve injuries. Surgery 140:1026-1032
This article is a response to the letter to the editor article available at doi: 10.1007/s00268-013-2269-1.

C. Kumar · A. Mishra $(\square)$

Department of Endocrine Surgery, Sanjay Gandhi Postgraduate

Institute of Medical Sciences, Raebareli Road,

Lucknow 226 014, India

e-mail: anjali@sgpgi.ac.in; anjali_mishra2000@yahoo.com 